\title{
Potential of breadfruit cultivation to contribute to climate-resilient low latitude food systems
}

\author{
Lucy Yang ${ }^{1}$, Nyree Zerega ${ }^{2,3}$, Anastasia Montgomery ${ }^{4}$, and Daniel E. Horton ${ }^{4,5}$
}

\author{
${ }^{1}$ Program in Environmental Sciences, Northwestern University \\ ${ }^{2}$ Program in Plant Biology and Conservation, Northwestern University \\ ${ }^{3}$ Chicago Botanic Garden
}

${ }^{4}$ Department of Earth \& Planetary Sciences, Northwestern University

${ }^{5}$ Institute for Sustainability and Energy at Northwestern University

\section{Keywords}

food security, climate change adaptation, bioclimactic niches, neglected and underutilized species (NUS), CMIP6, species distribution modeling, breadfruit

\section{Abstract}

The number of people in food crisis around the world is increasing, exacerbated by the challenges of COVID-19 and a rapidly changing climate. Major crop yields are projected to decrease in low-latitude regions due to anthropogenic climate change, making tropical and sub-tropical food systems particularly vulnerable to climate shocks. Increased cultivation of breadfruit (Artocarpus altilis), often categorized as a neglected and underutilized species (NUS), has been suggested as an agricultural adaptation pathway for food insecure tropical and subtropical regions, due to its potential to enhance climate resilience and overall sustainability of low-latitude agricultural systems. To better understand breadfruit's cultivation suitability and geographic range in current and future climates, we employ a diverse set of observations

and models to delineate the current climatically viable breadfruit range and assess the climatically viable breadfruit range in the future (2061-2080) under stabilization and high emission scenarios. We find that 
the area of suitable breadfruit range within the tropics and subtropics is projected to decrease $\sim 4.4 \%$ in the stabilization scenario and $\sim 4.5 \%$ in the high emission scenario. In Southeast Asia and the Pacific Islands, yield quality and consistency show minimal decreases under the high emission scenario, with increases in total suitable area under both scenarios. In contrast, in Latin America and the Caribbean, the current range of breadfruit suitability is projected to contract $\sim 10.1-11.5 \%$ (stabilization-high emission). Present and future model suitability outputs suggest that opportunities to successfully expand breadfruit cultivation over the next several decades exist in sub-Saharan Africa, where food insecurity is coincidentally high. However, in all regions, high emission scenario conditions reduce the overall consistency and quality of breadfruit yields compared to the stabilization scenario. Our results have the potential to inform global food security adaptation planning and highlight breadfruit as an ideal NUS to incorporate in food security adaptation strategies in a changing climate.

\section{Introduction}

The number of people in the world lacking regular access to nutritious and sufficient food has been challenges and increased the prevalence of undernourishment $(\mathrm{PoU})$ by $+1.5 \%$ to $\sim 9.9 \%$ in $2020(1,2)$. Food insecurity has increased in all global regions since 2014, except in North America and Europe, and the world is considerably off track to achieve the UN's global goal of Zero Hunger by 2030 (3). Climate change is a major driver of the observed rise in global hunger (4), with both gradual climatic change and punctuated shocks working to multiply threats and disrupt the food system at various levels, most notably food production and availability, but also in terms of access, quality, utilization, and stability (5). Climate adaptation solutions are needed to lessen risk in the global agricultural production system, particularly in regions with high populations of undernourished peoples (6). 
51 in the tropics and sub-tropics. Studies suggest that the agricultural adaptations made between 1981-2010 were insufficient to offset the negative impacts of climate change on common staple yields and production losses (e.g., wheat, rice, soybean, and maize), particularly at lower latitudes (7). While the geography of these major crops may expand to higher-latitudes under various climate change scenarios over the $21^{\text {st }}$ century (8), production of major crops in low latitudes is projected to be consistently and significantly negatively impacted (9-11), leading to a projected decrease in food availability and dietary diversity in tropical and subtropical regions (12). Furthermore, many of the world's current food security challenges lie within tropical latitudes, where anthropogenic warming is also projected to impact agricultural production most substantially $(6,12)$. These regions are particularly sensitive to increases in temperature due to low historical variability, with the time of emergence (TOE) of unprecedented temperature and precipitation regimes arriving earlier in terrestrial tropical biomes, compared to higher latitude regions, and potentially crossing a signal-to-noise threshold of 2 as early as the 2020s (13-15). Tropical agricultural production has already been adversely affected by extreme weather events and increased climatic variability, and yields will likely worsen with increased temperature stress and rainfall variability (16). Given these realized and projected impacts on staple crops, scaling up production of NUS has been suggested as an important adaptation measure in food-insecure regions. Expansion of NUS agriculture has the potential to enhance the climate resilience of food systems while simultaneously improving other negative environmental and social characteristics of current global food systems, including improving global crop and varietal diversity, increasing water efficiency, reducing excessive use of agrochemicals, increasing more locally produced food, and implementing practices that protect and conserve traditional knowledge and biodiversity (6).

A traditional crop originating in Oceania, where it is an important and widely used staple, breadfruit is a tropical NUS in other regions where it has a promising role in alleviating present and future food insecurity and improving the overall sustainability and resiliency of tropical and sub-tropical food systems $(17,18)$. Breadfruit offers practical advantages in low-latitude regions as a nutritious "superfood" grown from a long-lived tree that does not need annual replanting, requires lower energy input to cultivate 
(especially when cultivated in sustainable agroforestry systems), sequesters carbon as a long-lived tree, and can be used as a staple food in a variety of dishes and cultural cuisines (19). Breadfruit compares favorably, in some cases surpassing, major staples (including wheat, rice, and corn) in both yield and nutritional content (20). Breadfruit also shows great potential to reduce economic barriers to food access when implemented as part of economically sustainable development strategies in food-insecure regions of the world (21). As such, breadfruit has been presented as a potential solution to the world hunger crisis and labeled a "superfood of the future" by popular media, although its potential implementation as a practical adaptation to food insecurity under a changing climate has not been thoroughly explored. That said, its potential for more intensive cultivation over its broad current range and expansion to new regions shows promise as a climate adaptation strategy for sustainable food systems. Because the most commonly grown breadfruit varieties are seedless and are clonally propagated via root cuttings, grafting, air layering, or micropropagation methods, they have little to no likelihood of becoming invasive when introduced to new regions. In fact, over the last more than $\sim 200$ years seedless varieties have been introduced to many tropical regions with no recorded invasive behavior.

Breadfruit is a domesticated crop with a rich global history, connecting various cultures and regions.

91 Its wild, seeded ancestor is believed to have originated in New Guinea, and the seedless breadfruit was

92 domesticated in the islands of Oceania, where hundreds of cultivars exist (22). Breadfruit played a major 93 role as a key staple food in the human colonization of these islands. By about 3,000 years ago humans had

94 reached Samoa and few-seeded and seedless varieties began to appear. When Hawaii was one of the last

95 Pacific islands to be colonized by humans (between 1400 and 1700 years ago), seedless breadfruit was

96 brought by Polynesian voyagers to islands, where it is known as "ulu" (23). Breadfruit continues to play a

97 large part of cultural and spiritual life throughout Oceania. Europeans encountered breadfruit in Oceania in

98 the 1500 s $(24)$. By the $18^{\text {th }}$ century it had been introduced to Central and South America, the Caribbean,

99 tropical Asia, and other tropical regions, and it remains especially important in the Caribbean today (25). 
farmers in sub-Saharan Africa are increasingly looking to breadfruit as a potential crop for alleviating local commercial commodity in most regions (e.g., parts of West Africa, Southeast Asia, Latin America, and

104 India) with major production areas limited to the Pacific and Caribbean Islands (Ragone, 2018). However, 105 interest in commercial uses is growing (27). climactic future.

To examine the adaptation potential of breadfruit cultivation, we evaluate current and projected

117 breadfruit niche suitability and assess the potential for range expansion and/or contraction using species 118 distribution modeling (SDM) and bioclimactic data. Given our knowledge of suitable climate conditions 119 for breadfruit cultivation, and our understanding that many of these underlying factors are undergoing 120 anthropogenically-driven changes, we use a weighted ensemble of six species distribution models (SDMs)

121 created using 7 selected bioclimactic variables (from BIOCLIM) to assess changes in future (2061-2080)

122 breadfruit suitability range using downscaled simulation data from 8 different General Circulation Models 123 (GCMs) from phase 6 of the Coupled Model Intercomparison Project (CMIP6) (29). SDMs that rely on 124 bioclimactic variables over the full extent of a species range facilitate a realization of the fundamental niche 125 rather than a realized niche. Consideration of seasonality and variability is useful in determining the 
126 fundamental niche of plant species, particularly when an SDM is applied to future climatic conditions. This

127 approach allows us to assess the potential range of breadfruit in our current climate where it has not yet

128 been introduced, as well as extrapolate breadfruit cultivation suitability in future climates. This ensemble

129 SDM approach in conjunction with ensemble GCM projections allows us to evaluate the inherent inter-

130 model differences/uncertainties in both steps of the process. Gaining an understanding of the SDM and

131 climatic uncertainties that constrain breadfruit's potential global range can facilitate policy design intended

132 to mobilize new adaptation strategies for more resilient low-latitude food systems.

\section{Materials and Methods}

\subsection{Species Distribution Modeling (SDM)}

To determine current and future breadfruit niche suitability, we used observations and

137 bioclimactic data to constrain 6 unique SDMs: Generalized Linear Model (GLM), Generalized Additive

138 Model (GAM), Multiple Adaptive Regression Splines (MARS), Random Forest (RF), Generalized

139 Boosted Model (GBM), and Maximum Entropy (MAXENT) using the Biomodhub/Biomod2 software

140 version 3.4.13 (2018/2021). A weighted-mean ensemble of SDMs was used to determine current

141 breadfruit niche suitability. The ensemble approach to species distribution modeling has gained

142 considerable popularity and is useful for examining which bioclimatic variables determine the

143 fundamental niche of breadfruit, allowing us to project this model to future scenarios and evaluate the

144 changed distribution of global breadfruit suitability (31).

146 Global Biodiversity Information Facility (GBIF) historical breadfruit (Artocarpus altilis) occurrence point

147 data (32-35). GBIF presence points are prone to sampling bias because it allows citizen science

148 contributions to the database. Citizen scientists are prone to misidentify A. altilis, particularly by

149 confusing the plant with its close relative, seeded breadnut (A. camansi). To limit this bias, we 
downloaded only those data points that were identified as part of herbarium specimens ("Preserved specimen") or that included picture documentation. We also filtered GBIF presence points using a number of screens. First, presence data that appeared under alternative names (taxonomic synonyms), e.g., A. communis, A. incisa, and A. incisus, were included. However, data of two close relatives (i.e., $A$. camansi and A. mariannensis) were not included (36). Next, we ran the GBIF points using default settings of the CoordinateCleaner, an R-package tailored for cleaning occurrence records from biological

156 collection databases (37). This package flags geographical coordinates that are overly imprecise or have

157 common problems (e.g., points assigned to country centroids due to automated geo-referencing, plants

158 belonging to botanical gardens or museums, etc.). We also added datapoints from a yield study in Jamaica

159 (Trees that Feed Foundation, 2020, unpublished data). Finally, we discarded duplicate points within 160 common grid cells to limit spatial bias. Ultimately, over half of the breadfruit presence points downloaded 161 from GBIF were removed. The remaining 431 presence points are used for the SDM ensemble training 162 and prediction.

To determine the climatic variables that best predict the occurrence of current breadfruit

164 distribution, we used the dataset of bioclimatic variables (BIOCLIM) for 1970-2000 from WorldClim

165 Version 2.1, a database of high-resolution global climate data (39). To prevent overfitting of the final

166 SDM, we examined the full BIOCLIM dataset of 19 variables and selected a subset of variables based on

167 their predictive performance in individual and paired runs. We selected variables largely following the

168 methodology detailed in Moat et al., 2017 using GLM and GAM, two of the six SDMs used for the final

169 ensemble. Boxplots, preliminary map projections, and evaluative metrics including sensitivity, specificity,

170 True Skills Statistics (TSS), relative operating characteristic curve (ROC), and Cohen's Kappa statistic

171 (KAPPA) were used to determine which combination of variables were best for model fit, i.e., which

172 combination of bioclimatic variables best predicted the observed range of breadfruit. After evaluating

173 variable performance, we tested resulting variable combinations for collinearity and multi-collinearity

174 using a threshold of $\mathrm{R}^{2}=0.8$ and reduced the selection to 7 variables (Table 1 ). Annual mean temperature 
175 (BIO7) and annual precipitation (BIO12) were among the highest performing variables in the preliminary 176 model runs using GLM and GAM. While environmental characteristics such as solar radiation and soil 177 quality also impact breadfruit growth, they are not used to constrain breadfruit suitability in this study. performed within these lesser latitudinal bounds. Despite this change, our analysis covers almost the of the species (41). A lesser geographical extent also increases the reliability of pseudoabsence data. We use a presence-only SDM that relies on pseudoabsence (background) points to model suitability because no reliable source of true absence data was available. The TSS scores of the three sets of pseudoabsence points we generated vary by 0.05 . Although we latitudinally limited the geographic extent of the SDM in favor of generating more accurate pseudoabsence points, it is still difficult to produce useful pseudoabsence data at this large extent, as evidenced by the concentration of pseudoabsence points in grid-cells of less-suitable categories (Supplementary Figure 1). randomly with a ratio of 70:30 to build training and testing data separately over ten runs. The same metrics of sensitivity, specificity, TSS, ROC, and KAPPA were used to evaluate model outputs. indicate problematic outcomes, such as overfitting. After evaluation, the final SDM configuration was 
used to produce our suitability predictions from ten runs and three replicates. The TSS threshold of 0.7 was used to remove poorly performing runs from all five models before producing a mean ensemble prediction weighted by TSS score. Our weighted ensemble of SDMs demonstrates robust present-range predictive power, characterizing the distribution of breadfruit presences indicated by GBIF data while

204 also predicting broader distribution within Africa and other previously unexamined regions with high 205 sensitivity $(0.96)$ and reasonable accuracy (specificity $=0.83$ ). The included SDMs in this study meet 206 established criteria $(\mathrm{TSS}=0.79, \mathrm{KAPPA}=0.81, \mathrm{ROC}=0.93)$.

\subsection{General Circulation Model (GCM) Data}

Projected climate data was then used to determine niche expansion/contraction under future

210 climate scenarios SSPs 2 and $5(43,44)$. We modeled the future projections over the time period of 2061-

2112080 using the Biomod2 package Ensemble Forecasting. The projection was performed with the same

212 seven selected BIOCLIM variables from the GCM data under two shared socioeconomic pathway

213 scenarios: SSP2-4.5 (stabilization GHG emission scenario) and SSP5-8.5 (high GHG emission scenario)

214 forcing scenarios from 8 different GCMs. The GCMs from CMIP6 were used based on availability in

215 WorldClim 2.1 and include BCC-CSM2-MR, CNRM-CM6-1, CNRM-ESM2-1, CanESM5, IPSL-CM6A-

216 LR, MIROC-ES2L, MIROC6, and MRI-ESM2-0.

\subsection{Analysis and Mapping}

The SDM outputs from the current (Figure 1) and the two future scenarios were processed and categorized into three: Good, Fair, and Unsuitable. Niche classes were chosen based on natural inflection

220 points and breaks between pseudoabsence and presence data (see Supplementary Figure 1). The division

221 between "Fair" and "Good" categories was placed at 50\% to approximately reflect the inflection point of

222 the data. The Good niche classifications assesses breadfruit suitability based on yield quality and 
224 Meanwhile, the Fair range is more liberal and represents climactic conditions that established trees will

225 likely withstand, ergo persistence is assumed likely.

\section{Results}

\subsection{SDM Prediction of Current Breadfruit Suitability Range}

Our weighted ensemble baseline SDM predicts niche suitability in all GBIF-identified locations of current breadfruit cultivation, as well as substantial swathes of the global tropics and subtropics where successful cultivation of breadfruit has not yet been confirmed. Predicted suitable areas for cultivation include large sections of Southeast Asia, Central America, northern South America, the Caribbean, and equatorial Africa (Figure 1a). Latitudinal limits of modeled suitability extend as far north as northeastern India in Asia and southern Florida in North America and stretch as far south as Chile in South America and New Zealand in the Pacific. These regions have previously been identified by the National Tropical Botanic

236 Garden (NTBG) as suitable for breadfruit cultivation based on current climatic conditions (45). Suitable

237 niches that extend into the higher latitudes of the tropics are largely concentrated along coastlines, in 238 agreement with available GBIF occurrence data (Figure 1a; black dots). Notable areas without widespread occurrence data that are identified as having robust potential for breadfruit cultivation include Cuba, equatorial Africa, the southeastern coastline of Africa, and the Malay peninsula. In Africa, the lack of occurrence data in GBIF may be explained by breadfruit's recent arrival to the continent, but recent successful introductions haven been made in Uganda, Kenya, Tanzania, and Ghana. While no GBIF records are recorded in Cuba, it is known to grow there $(26,46,47)$. characterize the climatic conditions within a grid cell. The environmental variables were selected based on evaluation scores on the Generalized Linear Models and Generalized Additive Models while controlling 
driven by three temperature-related bioclimatic variables (TSS: 60.9). The annual temperature range, defined as the difference between the maximum temperature of the warmest month and the minimum temperature of the coldest month is the predominant prediction contributor (Figure 4c; TSS: 40.1). Secondary contributors include the mean diurnal temperature range (Figure 4a; TSS: 9.2) and the mean temperature of the coldest month (Figure 4g; TSS: 11.5). The four remaining contributing variables - annual precipitation, and precipitation during the driest, warmest, and coldest quarters - are lesser contributors relative to the temperature variables (Figure d-g; TSS: 6.1-7.0). statistical thresholding to subdivide the SDM suitability scores into Unsuitable, Fair, and Good categories

258 (Supplementary Figure 1). The unsuitable niche classification marks areas where breadfruit cultivation is barely possible to impossible, whereas fair classification marks areas where breadfruit cultivation is possible but yield and quality may be negatively affected by adverse seasonal weather conditions (e.g., low rainfall or high temperatures). Good niche classification indicates where breadfruit cultivation has the potential for consistent, high quality yields that are less likely to be affected by adverse weather conditions. For the lower threshold, between unsuitable and fair, we set the cut-off at the inflection point where an increase in model suitability values and the cumulative percentage of all (including pseudoabsence and occurrence) points plateaus, which resulted in the loss of four ground control points. The division between Fair and Good categories indicates a second inflection point where model suitability values begin to substantially increase. 1b-g) but show notable differences in categorizing the level of breadfruit suitability within these ranges. Across the 6 SDMs, there is only a $3.3 \%$ difference in the total "suitable" land area, although the classification of suitable land into either Fair or Good is less consistent, with $\sim 33.1-64.0 \%$ of the total suitable area identified as Fair depending on SDM and $\sim 36.0-66.9 \%$ classified as Good. When considering 
"Fair", while RF (66.9\%, 8.4M km² Good; 33.1\%, 17.0M km² Fair) and GBM (63.9\%, 16.2M km² Good;

$\mathrm{SDM}$, it is known to underestimate the probability of occurrence within areas of observed presence, while overestimating in areas without known presence (48). Several MAXENT runs (6 out of 30) were removed from the final weighted SDM ensemble due to low TSS scores, likely due to a lack of convergence. Marginal areas of Fair suitability are consistently identified by all 6 SDMs in the same locations (e.g., New Zealand, southwestern coast of Africa, Chile). Southeast Asia, Oceania, and the Pacific Islands are also consistently valued with the highest proportion of Good to Fair suitability. The 6 SDMs demonstrate consistent suitability coverage and patterns in regional Good to Fair suitability, although specific values differ.

Using the weighted-ensemble projection, we focus our narrative on comparative breadfruit suitability in three main regions: Asia and the Pacific Islands, the Caribbean and Latin America, and Africa. Compared to the averaged global proportion of area with Good $\left(51.9 \%, \sim 14 \mathrm{M} \mathrm{km}^{2}\right)$ to Fair $(48.1 \%, \sim 12 \mathrm{M}$ proportion of Good $\left(77.4 \%, \sim 2.8 \mathrm{M} \mathrm{km}^{2}\right)$ to Fair $\left(22.6 \%, \sim 800 \mathrm{~km}^{2}\right)$ quality, although Pacific Islands such

291 as Hawaii also show similarly high levels of $\operatorname{Good}\left(87.7 \%, \sim 30 \mathrm{k} \mathrm{km}{ }^{2}\right)$ to Fair $\left(12.3 \%, \sim 4 \mathrm{k} \mathrm{km}^{2}\right)$ area . In

292 Latin America and the Caribbean, island countries show high coverage of suitable area $\left(99.2 \%, \sim 2.3 \mathrm{M} \mathrm{km}^{2}\right)$

293 while $51.7 \%\left(\sim 11.7 \mathrm{M} \mathrm{km}^{2}\right)$ of the overall land area in Latin America and the Caribbean is projected to be 294 suitable. $41.3 \%$ of these suitable areas are classified as Good and $58.7 \%$ as Fair. In Africa, $20.8 \%$ of the 295 continent is projected to be suitable for growing breadfruit, with $45.4 \%$ of this land showing Good and 54.6\% 296 showing Fair suitability. This baseline SDM prediction gives a comprehensive picture of the range and 297 quality of suitable breadfruit-growing areas in various low-latitude regions of the world. 

scenario (44.4\%) than the stabilization scenario (32.1\%) (Figure 2). We find a $4.7 \%$ decrease in weighted ensemble SDM suitable breadfruit range $\left.(\sim 1.2 \mathrm{M} \mathrm{km})^{2}\right)$ in the stabilization scenario and a $4.5 \%$ decrease $\left(\sim 1.2 \mathrm{M} \mathrm{km}^{2}\right)$ under high emission scenario conditions (Figure 3$)$. However, the total area of "winners" and "losers" in terms of overall breadfruit suitability changes largely balance on a global scale. increases $\sim 0.7 \%\left(\sim 23 \mathrm{k} \mathrm{km}^{2}\right)$ under the stabilization scenario and $\left.0.8 \%(\sim 30 \mathrm{k} \mathrm{km})^{2}\right)$ under the high emission

311 scenario in Southeast Asia, although this increase in area is accompanied by a decrease in quality $(2.6 \%$ 312 and 8.7\%) and reduction in total Good area. In Asia and the Pacific Islands more broadly, total suitable 313 breadfruit area increases $\sim 2.8 \%\left(\sim 144 \mathrm{k} \mathrm{km}^{2}\right)$ and $\left.\sim 4.1 \%(\sim 214 \mathrm{k} \mathrm{km})^{2}\right)$, showing areas of potential expansion

314 in the upper and lower latitudinal limits of this region (Figure 2C, D). The majority of suitable breadfruit315 growing area is projected to persist in equatorial Africa, although with lower resilience potential to future 316 climate conditions than in Southeast Asia (1.5-3.4\% reduction in total suitable area and 58.2-70.0\% 317 reduction in Good area depending on emissions scenario). In both the stabilization and high-emission 318 scenarios, the baseline suitability range within equatorial Africa expands northward while the southern 319 bounds of breadfruit suitability are projected to contract. However, Latin America and the Caribbean are 320 projected to experience the largest magnitude range reduction on both the stabilization (10.1\%) and high 321 emission pathways (11.5\%). These range reductions appear to be concentrated in specific areas, particularly 322 in the Yucatan peninsula and southwestern Brazil. While Caribbean islands experience minimal contraction 323 of the overall suitable breadfruit-growing area (1.4-1.6\% reduction) under either emission pathway, the 324 quality of these conditions may decrease significantly (50.6-72.5\% reduction in Good area). Despite 325 regional variation, a large portion of global suitable breadfruit range is projected to persist in both scenarios 
326 (particularly in Africa and Asia and the Pacific Islands), suggesting that (1), established trees will likely 327 withstand future climatic conditions in most of the tropics and subtropics and (2) there is room for expanded 328 cultivation of breadfruit across a broad section of the global tropics and subtropics in Africa. However, a 329 greater decrease in quality but not necessarily a greater decrease in total area of suitability is projected under 330 the high emissions scenario in all regions.

Projected expansion of breadfruit suitability is driven by increases in seasonal temperature and precipitation. Increased precipitation during the coldest quarter (BIO19, Fig. 4t, u) as well as general increases in annual precipitation (BIO12, Fig. 4k,1) drive potential expansion of suitable breadfruit area at the perimeter of the baseline suitable range. Meanwhile, decreases in precipitation of the warmest quarter (BIO18) drive contraction of suitable breadfruit range in Central and South America (Fig. 4q, r). Mean Diurnal Range shows little change in Southeast Asia but increases in areas of expansion and decreases in areas of contraction and reduced breadfruit suitability (Fig. 4b, c).

To characterize the structural uncertainty of our breadfruit projections, we use our CMIP6 ensemble of opportunity and define projection confidence according to ensemble member agreement (i.e., 4-5 340 members agree - Strong, 6+ members agree $=$ Very Strong). Projections of future suitability show Very

341 Strong GCM agreement over the majority of the persistent range of breadfruit suitability under the 342 stabilization scenario (92.8\%) and high-emission scenario (90.5\%), with a larger area of weak GCM 343 agreement under the high-emission scenario. Weak SDM agreement ( $<4$ members agree) only characters $3445.1 \%$ of the persisting suitable range under the high-emission scenario and $3.6 \%$ of the suitable range under 345 the stabilization scenario. Strong and Weak agreement is concentrated at the outer fringes of breadfruit 346 distribution and most significantly in central South America in the Mato Grosso Plateau and eastern Africa 347 in the Ethiopian highlands (Figure 3). This finding suggests higher levels of uncertainty in areas of higher 348 elevation, although breadfruit suitability is projected to persist in the Andes in South America. Areas of 349 potential expansion also overlap with the areas of greatest uncertainty. In future scenarios, South Asia and 350 South America exhibit the greatest variability in area among GCMs (Figure 4). However, the majority of 
future global breadfruit cultivation in both scenarios demonstrates strong (4-5) to Very Strong (6+) agreement among the 8 GCMs in both scenarios.

\section{Discussion}

Our SDM prediction captures known locations of breadfruit while also suggesting potential expansion for the crop into food-insecure regions, most notably within Sub-Saharan Africa. While previous studies have attempted to constrain global and regional distributions of breadfruit suitability $(18,45)$, direct and rainfall (Ragone, 2006). While this study did not assess the impacts of climate change, their results on the current distribution of suitable cultivation range is in good agreement with our SDM-based findings. Mausio et al. (2020) further used fuzzy-set models to extrapolate breadfruit suitability from environmental parameters derived in Hawaii. Their work offers a useful comparison of an alternative approach to modeling breadfruit suitability by incorporating FAO EcoCrop parameters and climate data from CMIP5, but it does

367 not address the impact of seasonal temperature and precipitation data on potential breadfruit distribution 368 under future scenarios.

Our SDM indicates that the differences between the high-emissions scenario and stabilization

370 scenario in terms of total breadfruit suitability area is minimal, however the high-emission scenario is

371 predicted to lead to more substantial reductions in suitability scores in most regions. These findings are

372 particularly important for tropical and subtropical regions (low to mid latitude regions) where impacts on 373 the production of conventional staple crops such as maize, wheat, soybean and rice are projected to be more negative than higher latitudes (49). Expanded cultivation of breadfruit in such regions may contribute to 
global food and economic security, as a locally produced staple food that can lead to greater independence from food imports.

Breadfruit shows the most promising resilience to future climactic conditions within its native extent in Asia, largely persisting in Southeast Asia and even showing potential areas of expansion within India and China. Culturally, breadfruit is also a significant traditional crop in many Pacific Islands including Hawaii, where it has been noted for its promising role as part of local biocultural restoration efforts

381 (Langston and Lincoln, 2018). Breadfruit can play an important role in local low-latitude food systems, 382 alleviating the yield losses of major crops such as rice, while promoting sustainable agroforestry systems.

383 However, the persistence of suitable conditions for growing breadfruit are most at risk in specific regions within Latin America, namely a section of the Yucatan peninsula and southwestern Brazil in the Mosso Plateau. These areas experience decreases in annual precipitation, with significant decreases in precipitation during the warmest quarter of the year. These areas also coincide with weak agreement among the $8 \mathrm{GCMs}$, with less than half agreeing on the magnitude of precipitation reduction. increased food security and independence in the present and more distant future for several Sub-Saharan countries. As a promising NUS, breadfruit could fill immediate and future needs to increase food security

393 in many tropical regions, especially as crops such as maize and rice become less suited to warming 394 conditions $(11,50)$. Breadfruit demonstrates resilience to uncertain climactic conditions in many tropical 395 food-insecure regions. This adaptation potential is further enhanced if breadfruit trees are well-established 396 and grown within sustainable agroforestry systems. Agroforestry systems can serve as both adaptation and 397 mitigation, contributing to food productivity while enhancing restoration by combining traditional growing 398 methods used by Pacific Islanders for centuries with modern horticultural techniques $(6,51)$. 
factors (seasonal temperature and precipitation variables) and does not include the potential influence of soil type, solar radiation, or elevated $\mathrm{CO}_{2}$ concentrations on breadfruit suitability. We are confident that the $45^{\circ} \mathrm{N}$ to $45^{\circ} \mathrm{S}$ swath covers the majority $(\sim 97 \%)$ of present and future suitable breadfruit range under these scenarios, capturing the fundamental niche and identifying new areas where breadfruit can be introduced or expanded globally. While additional presence observations may improve the performance of our model, most studies agree that sample size effects usually become less critical above 50 presence points

407 (Guisan et al., 2017). Ideally, models of habitat suitability should also be based on measurements of population fitness at each geographic location. However, this would prevent the use of reliable data available in natural history collections. Although data points from GBIF were cleaned and filtered, absence data and rigorous groundtruthing would further improve the performance of the individual models that made up the final SDM ensemble. When projecting to future conditions, we were limited to using 412 realizations from relatively few (8) CMIP6 GCMs from WorldClim v.2.1 which likely limits the range of 413 internal variability and structural uncertainty considered in our projections. the next several decades, especially as rapid population growth is projected to intensify food insecurity and undernourishment across the continent (52). Closing the yield gap via sustainable intensification of

417 agriculture which utilizes NUS such as breadfruit may be critical in preventing future catastrophic 418 circumstances. Prioritizing a rich diversity of NUS over staple crops such as wheat, maize, and rice will 419 lead to healthier diets and improved nutrition and contribute to sustainable development (53). Similar 420 studies have examined the potential distribution of NUS under climate change, including 4 neglected and 421 underutilized fruit species (NUFS) in Sri Lanka and a yam species in Benin $(54,55)$, but few have examined 422 the viability of expanding cultivation of NUS across different continents at a global scale. As a long-lived 423 crop that can be grown and used locally, breadfruit offers an opportunity for various low-latitude 424 communities around the world to improve the resilience of their local food systems. By building agroforestry systems around breadfruit, low-latitude regions can avoid the pitfalls of strictly monoculture 


\subsection{Conclusion}

Our model of breadfruit niche suitability has the potential to provide projections useful for both

430 short-term decision making and long-term adaptation planning. Because breadfruit cultivation has not yet

431 expanded into its full suitable range, this crop has the potential to alleviate present and future food security

432 burdens, particularly in food-insecure countries in equatorial Africa. Although breadfruit growers may need

433 to contend with a certain level of reduced quality of yields in the future, suitable climatic conditions for

434 breadfruit cultivation exists across a broad range of the tropics and subtropics and persist for the next several

435 decades regardless of emissions pathway, indicating that it is a reliable and promising NUS to implement

436 as a climate adaptation strategy. Depending on scale of production, breadfruit itself may even play a role in

437 contributing to climate change mitigation due to its significant carbon sequestration benefits.

\section{Acknowledgments}

440 Research presented in this paper was supported by Summer Undergraduate Research and Conference

441 Travel Grants from Northwestern University's Office of the Provost to LY. The authors declare that there 442 is no conflict of interest. 


\section{References}

445 1. Diffenbaugh NS, Field CB, Appel EA, Azevedo IL, Baldocchi DD, Burke M, et al. The COVID-19

446 lockdowns: a window into the Earth System. Nat Rev Earth Environ. 2020 Sep;1(9):470-81.

447 2. FAO, IFAD, UNICEF, WFP, and WHO. The State of Food Security and Nutrition in the World $448 \quad$ 2021. Rome: FAO; 2021.

449 3. Global Network Against Food Crises, FSIN. Global Report on Food Crises [Internet]. 2020 [cited 2021 Mar 29]. Available from: https://www.wfp.org/publications/2020-global-report-food-crises

4. FAO, IFAD, UNICEF, WFP, WHO. The State of Food Security and Nutrition in the World: Building climate resilience for food security and nutrition. Rome, Italy: FAO; 2018. 181 p.

5. Vermeulen SJ, Campbell BM, Ingram JSI. Climate Change and Food Systems. Annual Review of Environment and Resources. 2012;37(1):195-222.

6. Mbow C, Rosenzweig C, Barioni LG. Food Security. In: Climate Change and Land: an IPCC special report on climate change, desertification, land degradation, sustainable land management, food security, and greenhouse gas fluxes in terrestrial ecosystems [Internet]. 2019 [cited 2021 Mar 29]. Available from: https://www.ipcc.ch/srccl/chapter/chapter-5/ associated with anthropogenic climate change for 1981-2010 compared with preindustrial levels. International Journal of Climatology. 2018;38(14):5405-17. 

the Intergovernmental Panel on Climate Change. 2014. p. 488-9.

9. Brown ME, Funk CC. Food Security Under Climate Change. Science. 2008 Feb 1;319(5863):5801.

10. Lobell DB, Burke MB, Tebaldi C, Mastrandrea MD, Falcon WP, Naylor RL. Prioritizing Climate Change Adaptation Needs for Food Security in 2030. Science. 2008 Feb 1;319(5863):607-10.

11. Zhao C, Liu B, Piao S, Wang X, Lobell DB, Huang Y, et al. Temperature increase reduces global yields of major crops in four independent estimates. PNAS. 2017 Aug 29;114(35):9326-31.

12. WFP. Climate impacts on food security and nutrition: a review of existing knowledge [Internet]. 2014 [cited 2021 Mar 29]. Available from: https://www.eldis.org/document/A73884

13. Diffenbaugh NS, Scherer M. Observational and model evidence of global emergence of permanent,

14. Tan X, Gan TY, Horton DE. Projected timing of perceivable changes in climate extremes for unprecedented heat in the 20th and 21st centuries. Climatic Change. 2011 Aug 1;107(3):615-24. CLIMATE SIGNALS. Geophys Res Lett. 2012 Jan;39(1):n/a-n/a.

16. Ericksen PJ, Thornton PK, Notenbaert AMO, Cramer L, Jones PG, Herrero MT. Mapping hotspots of climate change and food insecurity in the global tropics [Internet]. CGIAR Research Program on Climate Change, Agriculture and Food Security; 2011 Jun [cited 2021 Mar 29]. Available from: https://cgspace.cgiar.org/handle/10568/3826 
17. Turi CE, Liu Y, Ragone D, Murch SJ. Breadfruit (Artocarpus altilis and hybrids): A traditional crop with the potential to prevent hunger and mitigate diabetes in Oceania. Trends in Food Science \& Technology. 2015 Oct 1;45(2):264-72.

18. Mausio K, Miura T, Lincoln NK. Cultivation potential projections of breadfruit (Artocarpus altilis) under climate change scenarios using an empirically validated suitability model calibrated in Hawai'i. PLOS ONE. 2020 May 22;15(5):e0228552.

19. Orwa C, Mutua A, Kindt R, Simons A, Jamnadass R H. Agroforestree database: a tree reference and selection guide version 4.0. Nairobi, Kenya: World Agroforestry Centre (ICRAF); 2010. 1 p.

20. Jones AMP, Ragone D, Aiona K, Lane WA, Murch SJ. Nutritional and morphological diversity of breadfruit (Artocarpus, Moraceae): Identification of elite cultivars for food security. Journal of Food Composition and Analysis. 2011 Dec 1;24(8):1091-102.

21. Omobuwajo TO. BREADFRUIT AS A KEY COMPONENT OF SUSTAINABLE LIVELIHOODS IN NIGERIA: PROSPECTS, OPPORTUNITIES AND CHALLENGES. Acta Hortic. 2007 Nov;(757):121-4.

22. Zerega N, Wiesner-Hanks T, Ragone D, Irish B, Scheffler B, Simpson S, et al. Diversity in the breadfruit complex (Artocarpus, Moraceae): genetic characterization of critical germplasm. Tree Genetics \& Genomes. 2015 Jan 20;11(1):4.

23. Kirch PV. On the Road of the Winds: An Archaeological History of the Pacific Islands before European Contact, Revised and Expanded Edition [Internet]. 2nd ed. University of California Press; 2017 [cited 2021 Sep 23]. Available from: https://www.jstor.org/stable/10.1525/j.ctv1xxsng 1904 Dec 1;20(12):649-52. 
506

507

508

509

510

511

512

25. Ragone D. Breadfruit.(Parkinson) Fosberg. Promoting the conservation and use of underutilized and neglected crops. 10. 1997;

26. Trees That Feed Foundation. Africa [Internet]. [cited 2021 Sep 7]. Available from: https://www.treesthatfeed.org/countries/africa/

27. Peters A. Why Patagonia wants you to eat breadfruit [Internet]. Fast Company. 2021 [cited 2021 Sep 7]. Available from: https://www.fastcompany.com/90620093/youve-probably-never-eatenbreadfruit-heres-why-patagonia-wants-to-change-that

28. Taylor M, McGregor A, Dawson B. Vulnerability of Pacific Island agriculture and forestry to climate change [Internet]. 2016 [cited 2021 Mar 29]. Available from: http://www.fao.org/familyfarming/detail/en/c/432913/

29. Eyring V, Bony S, Meehl GA, Senior CA, Stevens B, Stouffer RJ, et al. Overview of the Coupled Model Intercomparison Project Phase 6 (CMIP6) experimental design and organization. Geoscientific Model Development. 2016 May 26;9(5):1937-58.

30. biomodhub/biomod2 [Internet]. biomod2 package, tools and scripts; 2021 [cited 2021 Mar 29]. Available from: https://github.com/biomodhub/biomod2

31. Hao T, Elith J, Guillera-Arroita G, Lahoz-Monfort JJ. A review of evidence about use and performance of species distribution modelling ensembles like BIOMOD. Diversity and Distributions. 2019;25(5):839-52.

32. GBIF Occurrence Download [Internet]. GBIF.org; [cited 2020 Nov 11]. Available from: https://doi.org/10.15468/dl.mas6f8

33. GBIF Occurrence Download [Internet]. GBIF.org; [cited 2019 Jul 15]. Available from: https://doi.org/10.15468/dl.fcoapd 
34. GBIF Occurrence Download [Internet]. GBIF.org; [cited 2019 Jul 15]. Available from: https://doi.org/10.15468/d1.jae0fb

35. GBIF Occurrence Download [Internet]. GBIF.org; [cited 2020 Nov 11]. Available from: https://doi.org/10.15468/d1.x5ubgu

36. Zerega N, Ragone D, Motley TJ. 10. Breadfruit Origins, Diversity, and Human-Facilitated Distribution. In: Motley T, editor. Darwin’s Harvest [Internet]. Columbia University Press; 2006 [cited 2021 Aug 1]. p. 213-38. Available from: https://www.degruyter.com/document/doi/10.7312/motl13316-011/html

37. Zizka A, Silvestro D, Andermann T, Azevedo J, Ritter CD, Edler D, et al. CoordinateCleaner: Automated Cleaning of Occurrence Records from Biological Collections [Internet]. 2020 [cited 2021 Mar 29]. Available from: https://CRAN.R-project.org/package=CoordinateCleaner

38. Trees that Feed Foundation. Breadfruit Yield Study in Jamaica, 2018-20 [Internet]. 2020 [cited 2021 Sep 28]. Available from: https://treesthatfeed.org/breadfruit-yield-study/

39. Fick SE, Hijmans RJ. WorldClim 2: new 1-km spatial resolution climate surfaces for global land areas. Int J Climatol. 2017 Oct;37(12):4302-15.

40. Moat J, Williams J, Baena S, Wilkinson T, Gole TW, Challa ZK, et al. Resilience potential of the Ethiopian coffee sector under climate change. Nature Plants. 2017 Jun 19;3(7):1-14.

41. Guisan A, Thuiller W, Zimmermann NE. Habitat Suitability and Distribution Models: With Applications in R [Internet]. Cambridge: Cambridge University Press; 2017 [cited 2021 Sep 28]. (Ecology, Biodiversity and Conservation). Available from: https:/www.cambridge.org/core/books/habitat-suitability-and-distributionmodels/A17F74A3418DBF9ADA191A04C35187F9 
42. Habitat suitability and distribution models applications $\mathrm{r} \mid$ Ecology and conservation $\mid$ Cambridge University Press [Internet]. [cited 2021 Mar 29]. Available from: https://www.cambridge.org/us/academic/subjects/life-sciences/ecology-and-conservation/habitatsuitability-and-distribution-models-applications-r?format=PB\&isbn=9780521758369

43. Fricko O, Havlik P, Rogelj J, Klimont Z, Gusti M, Johnson N, et al. The marker quantification of the Shared Socioeconomic Pathway 2: A middle-of-the-road scenario for the 21 st century. Global Environmental Change. 2017 Jan 1;42:251-67.

44. Kriegler E, Bauer N, Popp A, Humpenöder F, Leimbach M, Strefler J, et al. Fossil-fueled development (SSP5): An energy and resource intensive scenario for the 21st century. Global Environmental Change. 2017 Jan 1;42:297-315.

45. Matthew P. Lucas, Ragone D. Will Breadfruit Solve the World Hunger Crisis? ArcNews [Internet]. 2012 [cited 2021 Jun 7]; Available from:

https://www.esri.com/news/arcnews/summer12articles/will-breadfruit-solve-the-world-hungercrisis.html

46. Berg CC, Corner EJH, Jarrett FM. Moraceae genera other than Ficus. Flora Malesiana - Series 1, Spermatophyta. 2006 Jan 1;17(1):1-146.

47. Miguel E, Castiñeiras L, Knüpffer H, Hammer K. A checklist of the cultivated plants of Cuba. Die Kulturpflanze. 1989 Jun 1;37(2):211-357.

48. Fitzpatrick MC, Gotelli NJ, Ellison AM. MaxEnt versus MaxLike: empirical comparisons with ant species distributions. Ecosphere. 2013;4(5):art55.

49. Levis S, Badger A, Drewniak B, Nevison C, Ren X. CLMcrop yields and water requirements: avoided impacts by choosing RCP 4.5 over 8.5. Climatic Change. 2018 Feb 1;146(3):501-15. 
50. Schlenker W, Roberts MJ. Nonlinear temperature effects indicate severe damages to U.S. crop yields under climate change. PNAS. 2009 Sep 15;106(37):15594-8.

51. Elevitch C, Ragone D. Breadfruit Agroforestry Guide: Planning and implementation of regenerative organic methods. 2018.

52. Hall C, Dawson TP, Macdiarmid JI, Matthews RB, Smith P. The impact of population growth and climate change on food security in Africa: looking ahead to 2050. International Journal of Agricultural Sustainability. 2017 Mar 4;15(2):124-35.

53. Hunter D, Borelli T, Beltrame DMO, Oliveira CNS, Coradin L, Wasike VW, et al. The potential of neglected and underutilized species for improving diets and nutrition. Planta. 2019 Sep 1;250(3):709-29.

54. Gbemavo DSJC, Assani Z, Idohou R, Laly J, Gbaguidi A, Dansi A. Modelling current agroecological zones for the cultivation of Dioscorea dumetorum (Kunth) Pax, a neglected and underutilized yam species in Benin (West Africa). Model Earth Syst Environ. 2021 Sep $1 ; 7(3): 2127-35$.

55. Ratnayake SS, Kumar L, Kariyawasam CS. Neglected and Underutilized Fruit Species in Sri Lanka: Prioritisation and Understanding the Potential Distribution under Climate Change. Agronomy. 2020 Jan;10(1):34. 

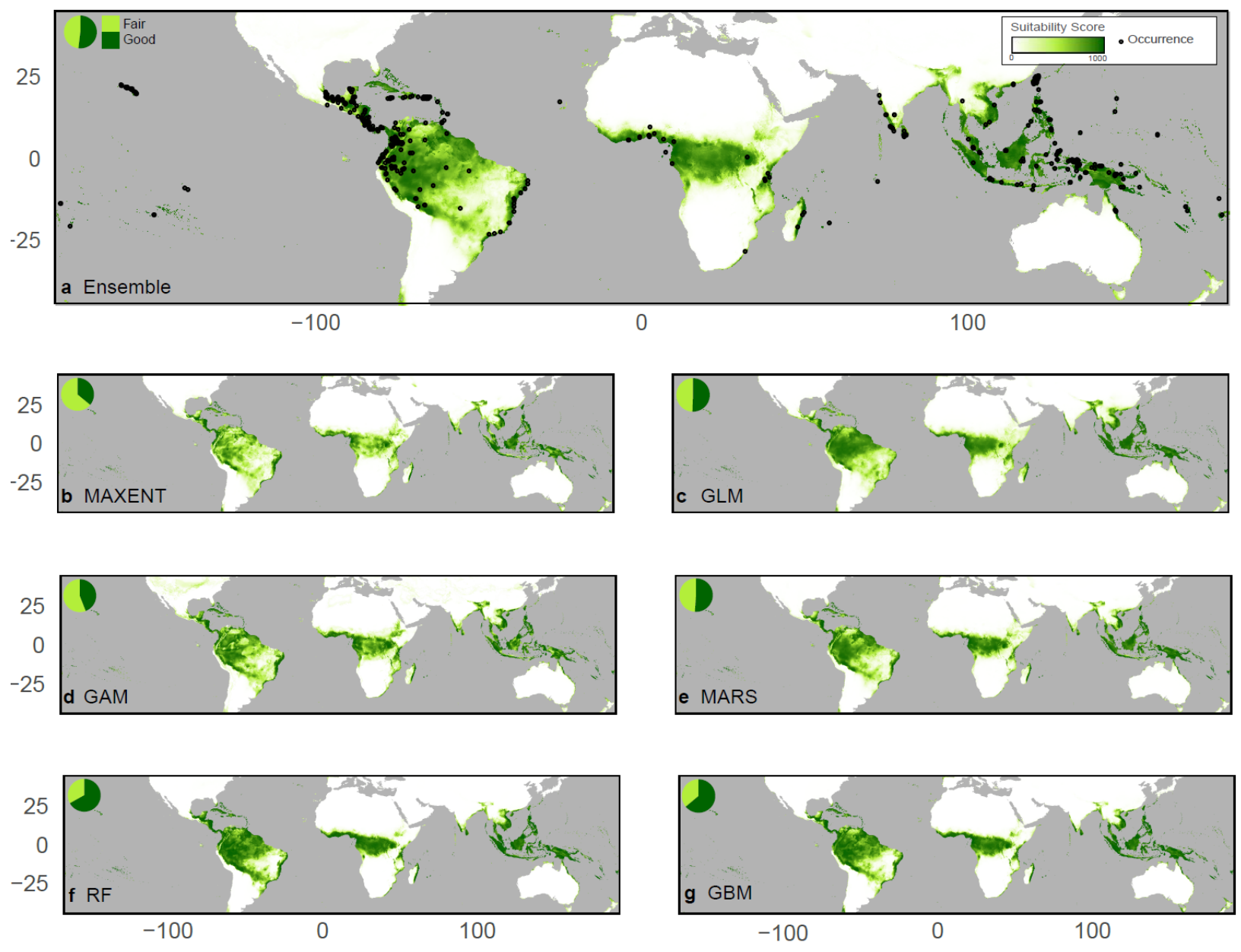

Figure 1. Range of current (1970-2000) breadfruit suitability in the global tropics and subtropics $\left(45^{\circ} \mathrm{N}\right.$ to $\left.45^{\circ} \mathrm{S}\right)$ as predicted from bioclimactic variables from 10 arcminute resolution WorldClim v2.1 data and filtered GBIF occurrence points. Climatic suitability of breadfruit cultivation is indicated by green shading ranging from 0 (fair) to 1000 (good). (A) The ensemble mean-weighted SDM and 6 different individual SDMs including $(B)$ MAXENT, $(C)$ GLM, $(D)$ GAM, $(E)$ MARS, $(F)$ RF, and $(G)$ GBM. Black dots in $(A)$ are observed occurrence points from GBIF. Pie charts in upper left of each plot indicate fraction of Fair (score $=250-750)$ to Good $($ score $=750+$ ) area. 

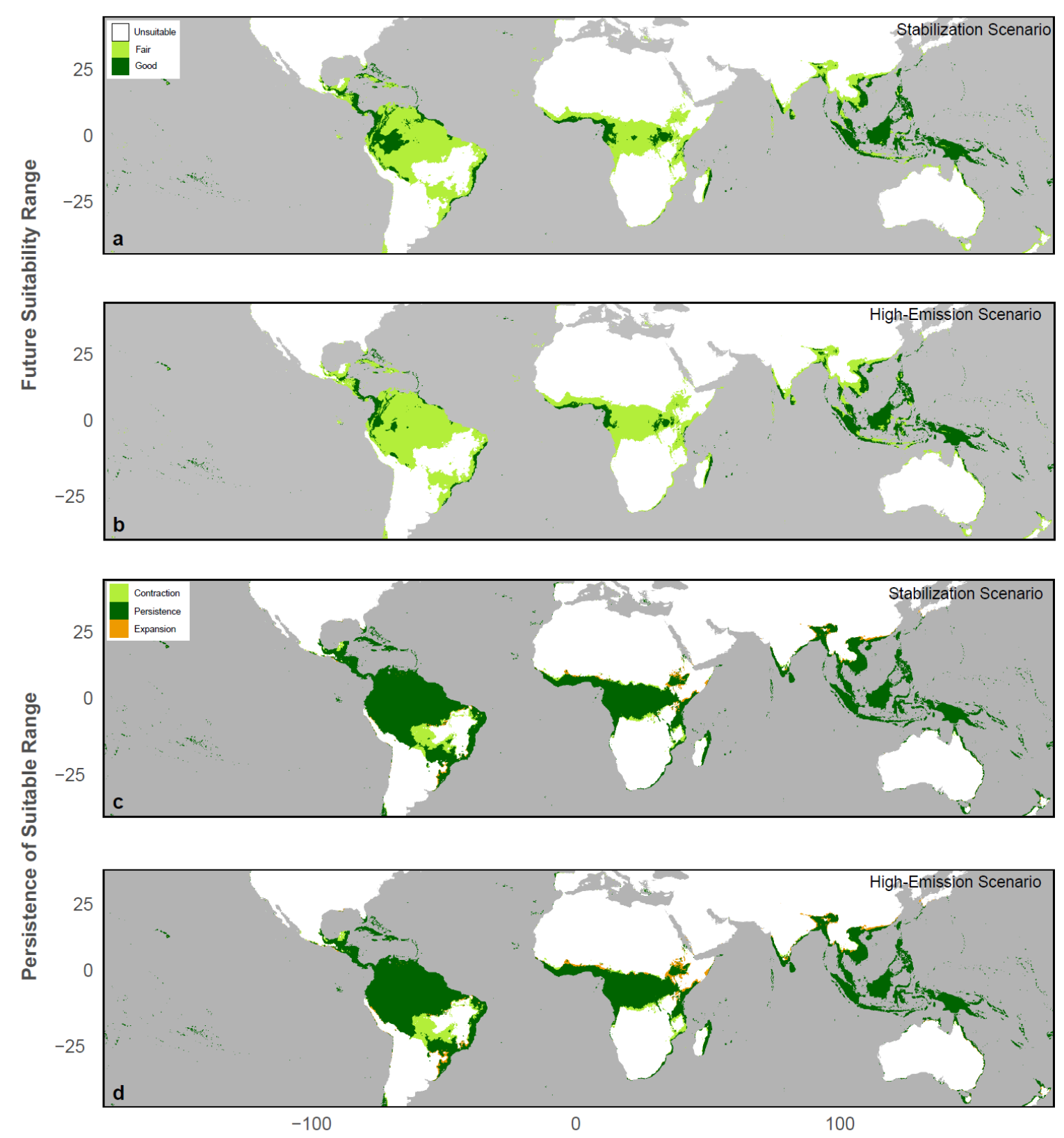

604 Figure 2. Future (2061-2080) breadfruit suitability range and change under stabilization and high-emission

605 scenarios. (a) Future suitability (Fair: score $=250-750$; Good: score $=750+$ ) of weighted SDM ensemble under

606 stabilization scenario (SSP2-4.5) and (b) high-emission scenario (SSP8-8.5) using averages from a CMIP6 ensemble

607 of opportunity from 8 GCMs. Change in suitable range (score $>250$ ) from baseline suitability score under (c)

608 stabilization scenario and (d) high-emission scenario. 

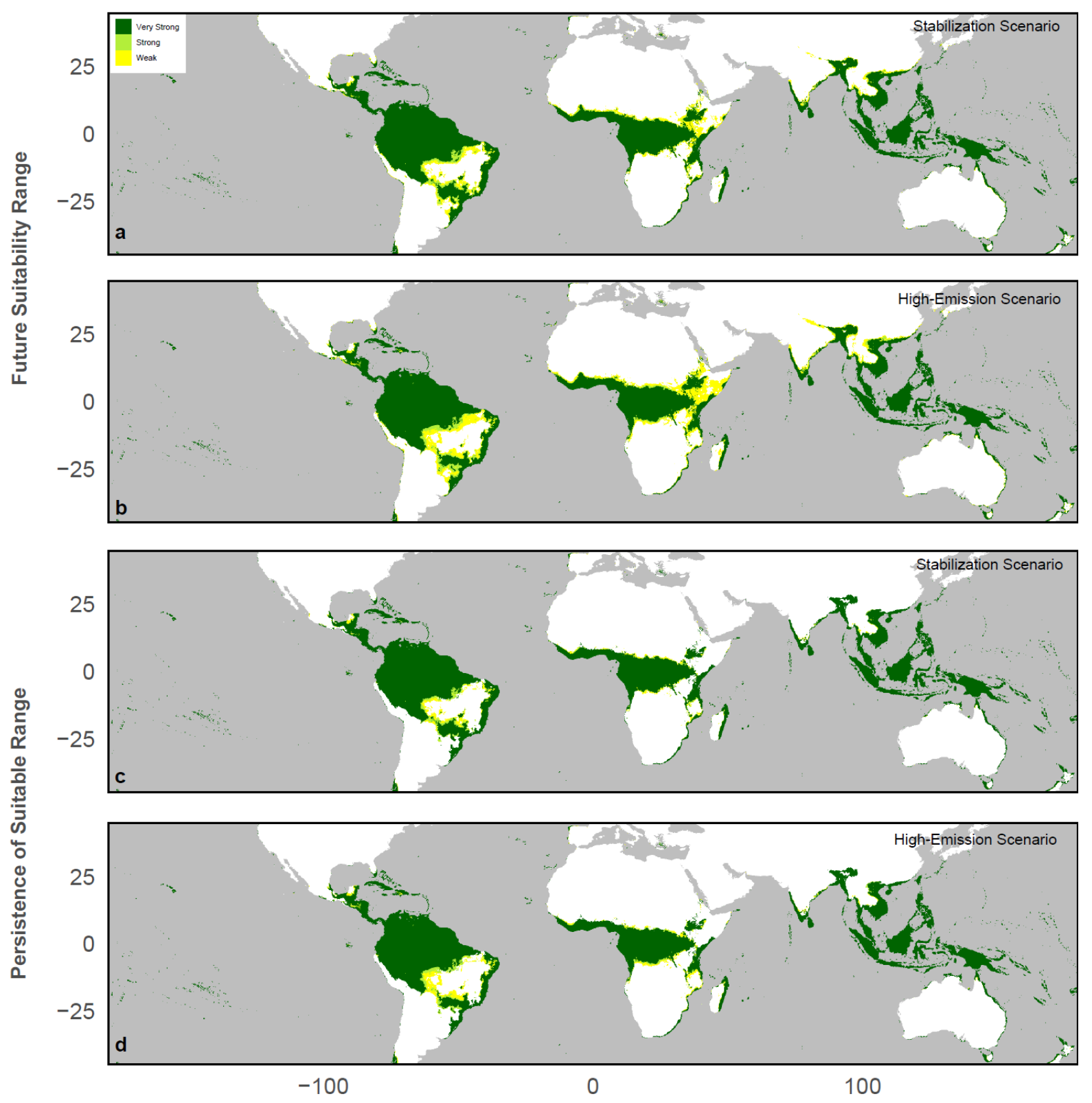

610 Figure 3. Change in suitable breadfruit area (value $>250$ ) between the ensemble baseline SDM (B) and the

611 stabilization (S) and high-emission (H) scenarios within various regions in the global tropics and subtropics,

612 including Asia and the Pacific Islands, Africa, and Latin America, with Weak (1-3 members), Strong (4-5 members)

613 and Very Strong (6+ members) CMIP6 GCM average agreement. 
bioRxiv preprint doi: https://doi org/101101/2021.10.01.462801. this version posted November 4 2021. The copyright holder for this preprint (which was not certified by peer review) is the author/funder, who has granted bioRxiv a license to display the preprint in perpetuity. It is made available under aCC-BY-NC-ND 4.0 International license.

BASELINE

BIO2 Mean Diurnal Range

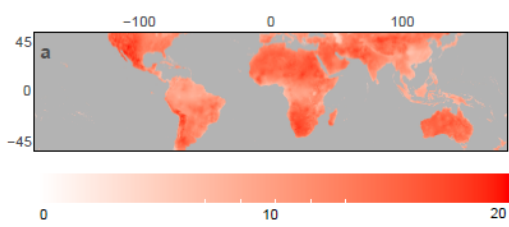

BIO7 Temperature Annual Range

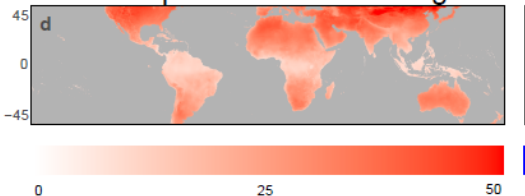

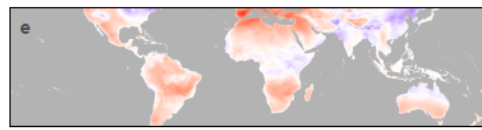

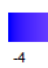

SSP245 (CHANGE)

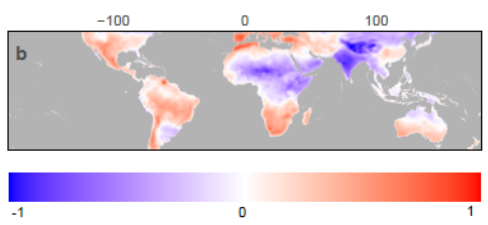

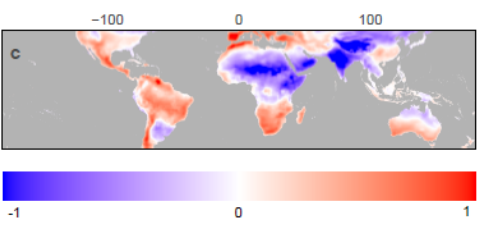
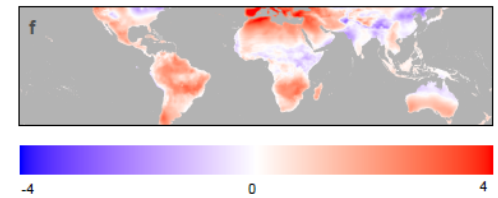

BIO11 Mean Temperature of Coldest Quarter
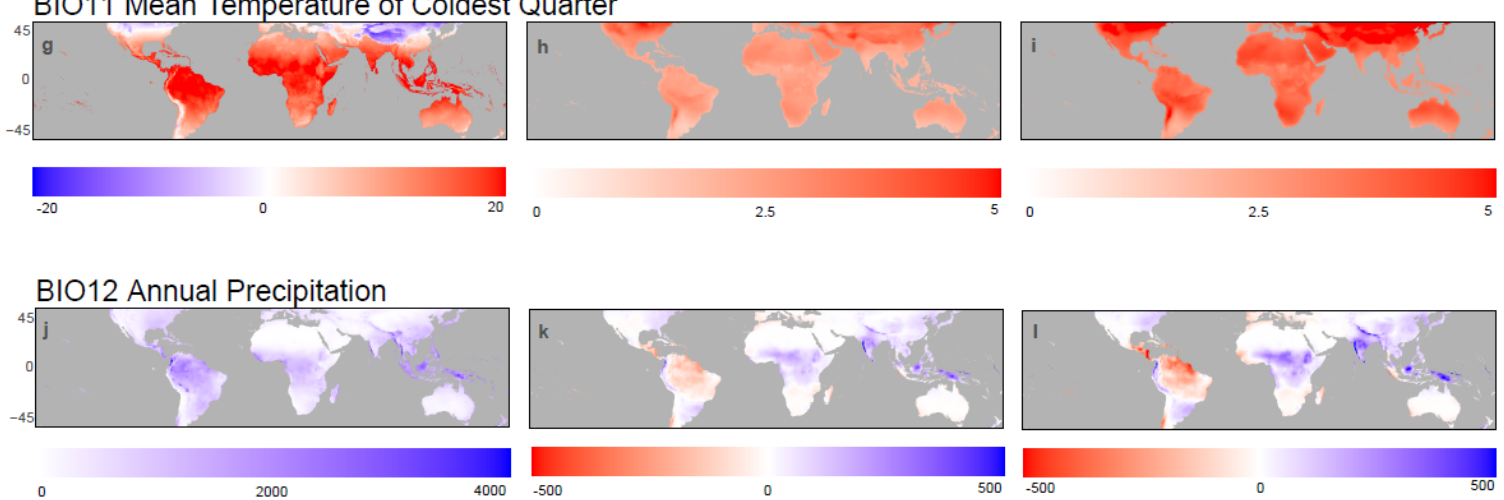

BIO17 Precipitation of Driest Quarter
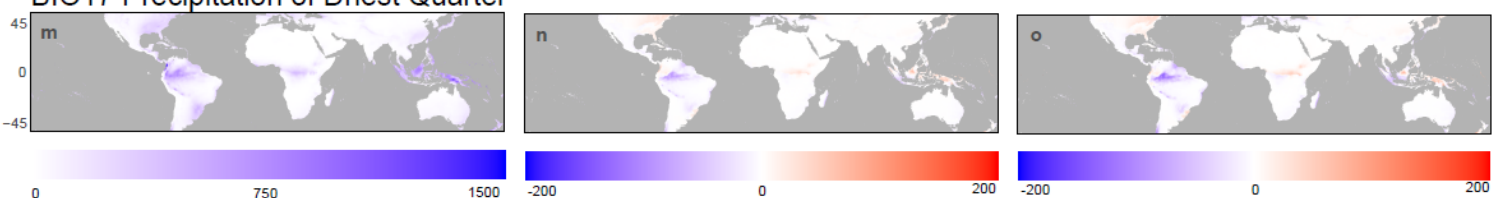

BIO18 Precipitation of Warmest Quarter
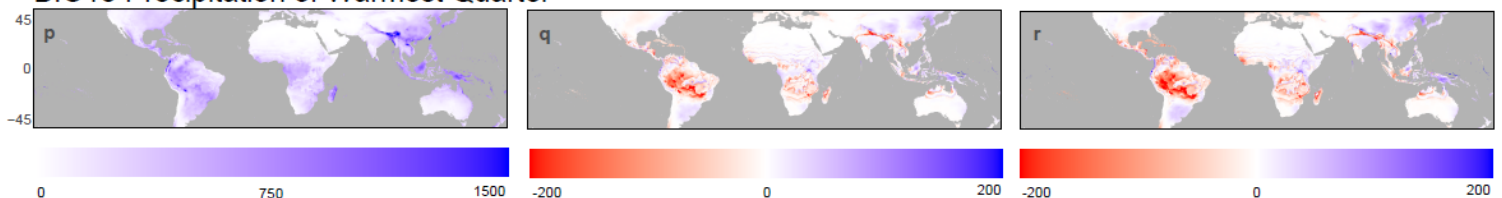

BIO19 Precipitation of Coldest Quarter
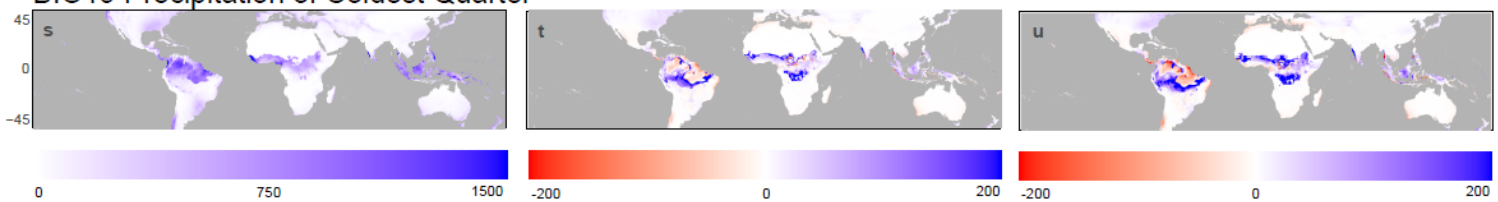

614 Figure 4. Difference Plots of Top BIOCLIM Contributors to SDM. Columns show the baseline (1970-2000)

615 bioclimatic variables (left) and the absolute difference of the specific bioclimatic variables from 2061-2080 under 
bioRxiv preprint doi: https://doi.org/10.1101/2021.10.01.462801; this version posted November 4, 2021. The copyright holder for this preprint

(which was not certified by peer review) is the author/funder, who has granted bioRxiv a license to display the preprint in perpetuity. It is made available under aCC-BY-NC-ND 4.0 International license.

616 SSP2-4.5 (middle) and SSP5-8.5 (right) scenarios of the CMIP6 ensemble of opportunity downscaled to 10

617 arcminute resolution from WorldClim v2.1. 


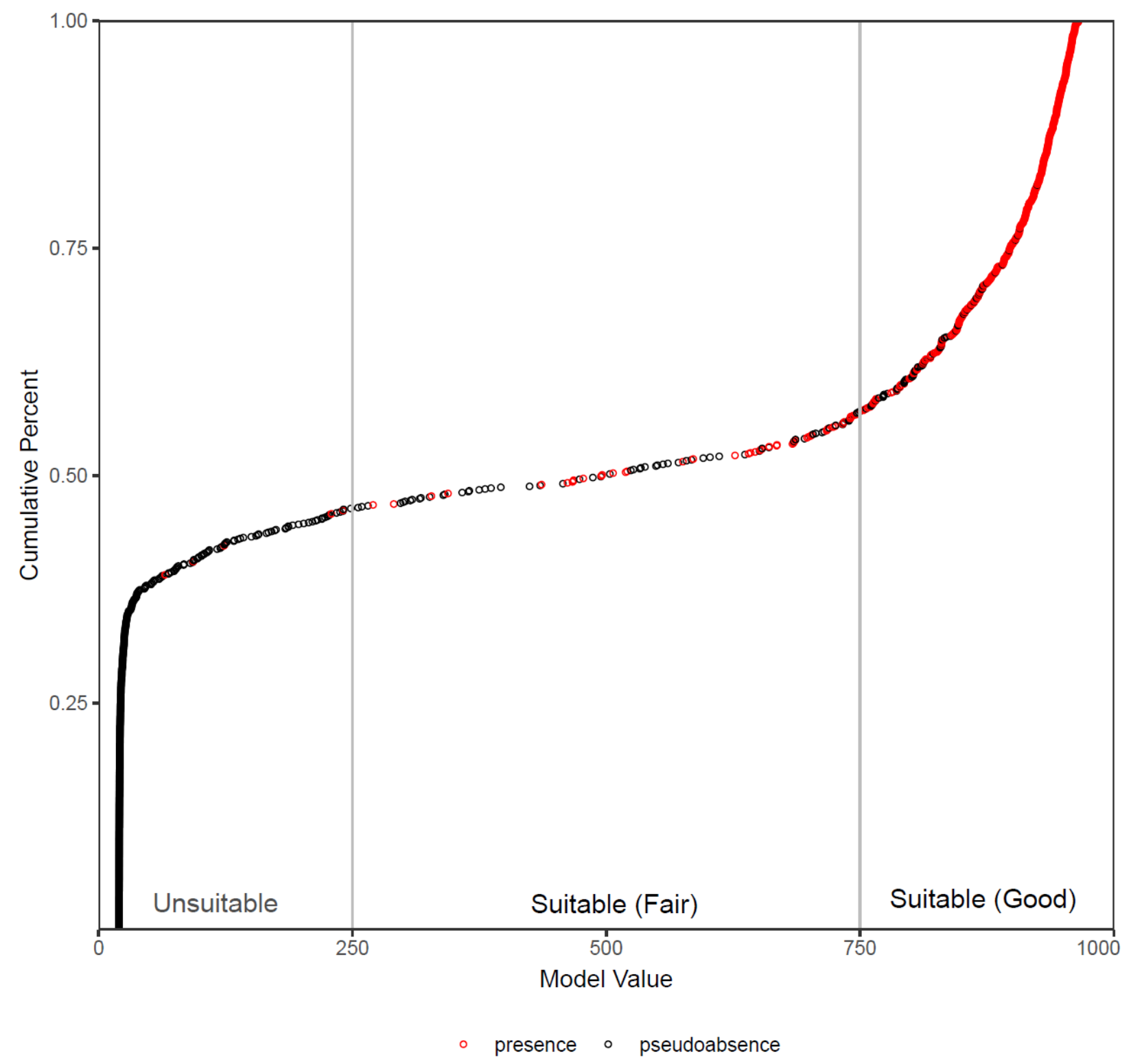

620 Supplementary Figure 1. Threshold metrics for breadfruit suitability used for SDM classification. Categories

621 are demarcated in relation to trends between cumulative percent of total number of points (presence and

622 pseudoabsence) and model suitability value (0-1000). The Fair (250-750) and Good (750-1000) suitability

623 categories are marked by greater prevalence of presence points, with 4 occurrence points categorized as unsuitable. 
bioRxiv preprint doi: https://doi org/10.1101/2021.10.01.462801. this version posted November 4, 2021. The copyright holder for this preprint (which was not certified by peer review) is the author/funder, who has granted bioRxiv a license to display the preprint in perpetuity. It is made available under aCC-BY-NC-ND 4.0 International license.

625 Supplementary Table 1. Relative importance (TSS) of 7 selected BIOCLIM variables within and across 6

626 individual SDMs in baseline (1970-2000) scenario.

\begin{tabular}{|l|l|l|l|l|l|l|l|l|}
\hline & Bioclimactic Variable & MAXENT & GLM & GAM & MARS & RF & GBM & Average \\
\hline BIO2 & Mean Diurnal Range & 0.201 & 0.046 & 0.123 & 0.081 & 0.063 & 0.042 & 0.093 \\
\hline BIO7 & $\begin{array}{l}\text { Temperature Annual Range (BIO5- } \\
\text { BIO6) }\end{array}$ & 0.312 & 0.543 & 0.403 & 0.381 & 0.312 & 0.454 & 0.401 \\
\hline BIO11 & $\begin{array}{l}\text { Mean Temperature of Coldest } \\
\text { Quarter }\end{array}$ & 0.194 & 0.052 & 0.191 & 0.124 & 0.098 & 0.033 & 0.115 \\
\hline BIO12 & Annual Precipitation & & & & & & & \\
\hline BIO17 & Precipitation of Driest Quarter & 0.121 & 0.027 & 0.106 & 0.055 & 0.031 & 0.025 & 0.061 \\
\hline BIO18 & Precipitation of Warmest Quarter & 0.150 & 0.063 & 0.107 & 0.026 & 0.038 & 0.016 & 0.067 \\
\hline BIO19 & Precipitation of Coldest Quarter & 0.185 & 0.012 & 0.104 & 0.069 & 0.034 & 0.016 & 0.070 \\
\hline
\end{tabular}


628 Supplementary Table 2. SDM Variability of Breadfruit Suitability across 6 individual and ensemble SDMs.

629 Suitability is categorized over $98280727 \mathrm{~km}^{2}$ of total land area constrained within the latitudes of $45^{\circ} \mathrm{N}$ to $45^{\circ} \mathrm{S}$.

\begin{tabular}{|c|c|c|}
\hline Suitability & SDM & Area $\left(\mathrm{km}^{2}\right)$ \\
\hline Fair & $\begin{array}{l}\text { MAXENT } \\
\text { GLM } \\
\text { GAM } \\
\text { MARS } \\
\text { RF } \\
\text { GBM } \\
\text { Ensemble }\end{array}$ & $\begin{array}{l}17743876 \\
14117175 \\
15835734 \\
12581785 \\
8411102 \\
9125204 \\
12725593\end{array}$ \\
\hline Good & $\begin{array}{l}\text { MAXENT } \\
\text { GLM } \\
\text { GAM } \\
\text { MARS } \\
\text { RF } \\
\text { GBM } \\
\text { Ensemble }\end{array}$ & $\begin{array}{l}9953293 \\
14455265 \\
12461001 \\
13168259 \\
16982621 \\
16180823 \\
13721639\end{array}$ \\
\hline Unsuitable & $\begin{array}{l}\text { MAXENT } \\
\text { GLM } \\
\text { GAM } \\
\text { MARS } \\
\text { RF } \\
\text { GBM } \\
\text { Ensemble }\end{array}$ & $\begin{array}{l}70583558 \\
69708287 \\
69983992 \\
72530682 \\
72887004 \\
72974700 \\
71833495\end{array}$ \\
\hline
\end{tabular}


630 Supplementary Table 3. GCM Variability in Breadfruit Suitability Under Stabilization and High Emissions

631 Scenarios of individual CMIP6 GCMs. All available downscaled GCMs at 10 arcminute resolution were accessed

632 from WorldClim v2.1. Breadfruit suitability is evaluated within land area constrained within the global tropics and

633 subtropics.

\begin{tabular}{|c|c|c|c|}
\hline Suitability & GCM & Area - SSP2-4.5 & Area - SSP5-8.5 \\
\hline \multirow[t]{8}{*}{ Fair } & BCC-CSM2-MR & 16127181 & 17010437 \\
\hline & CanESM5 & 16386867 & 17383498 \\
\hline & CNRM-CM6-1 & 15938225 & 17329833 \\
\hline & CNRM-ESM2-1 & 16025173 & 17377793 \\
\hline & IPSL-CM6A-LR & 15660300 & 17401963 \\
\hline & MIROC-ES2L & 14538802 & 15165247 \\
\hline & MIROC6 & 14200092 & 15245630 \\
\hline & MRI-ESM2-0 & 13900888 & 15981020 \\
\hline \multirow[t]{8}{*}{ Good } & BCC-CSM2-MR & 9364025 & 8533701 \\
\hline & CanESM5 & 8101903 & 7002352 \\
\hline & CNRM-CM6-1 & 9571089 & 8025798 \\
\hline & CNRM-ESM2-1 & 9442967 & 7896402 \\
\hline & IPSL-CM6A-LR & 10249666 & 8673592 \\
\hline & MIROC-ES2L & 10186645 & 9507514 \\
\hline & MIROC6 & 10498834 & 8805485 \\
\hline & MRI-ESM2-0 & 10430547 & 8993401 \\
\hline \multirow[t]{4}{*}{ Unsuitable } & BCC-CSM2-MR & 72784947 & 72732016 \\
\hline & CanESM5 & 73778272 & 73881192 \\
\hline & CNRM-CM6-1 & 72765857 & 72919540 \\
\hline & CNRM-ESM2-1 & 72807031 & 73000976 \\
\hline
\end{tabular}


bioRxiv preprint doi: https://doi.org/10.1101/2021.10.01.462801; this version posted November 4, 2021. The copyright holder for this preprint (which was not certified by peer review) is the author/funder, who has granted bioRxiv a license to display the preprint in perpetuity. It is made available under aCC-BY-NC-ND 4.0 International license.

\begin{tabular}{|lcc|}
\hline IPSL-CM6A-LR & 72358041 & 72192452 \\
MIROC-ES2L & 73541595 & 73594281 \\
MIROC6 & 73576245 & 74224056 \\
MRI-ESM2-0 & 73944719 & 73301732 \\
\hline
\end{tabular}

634 

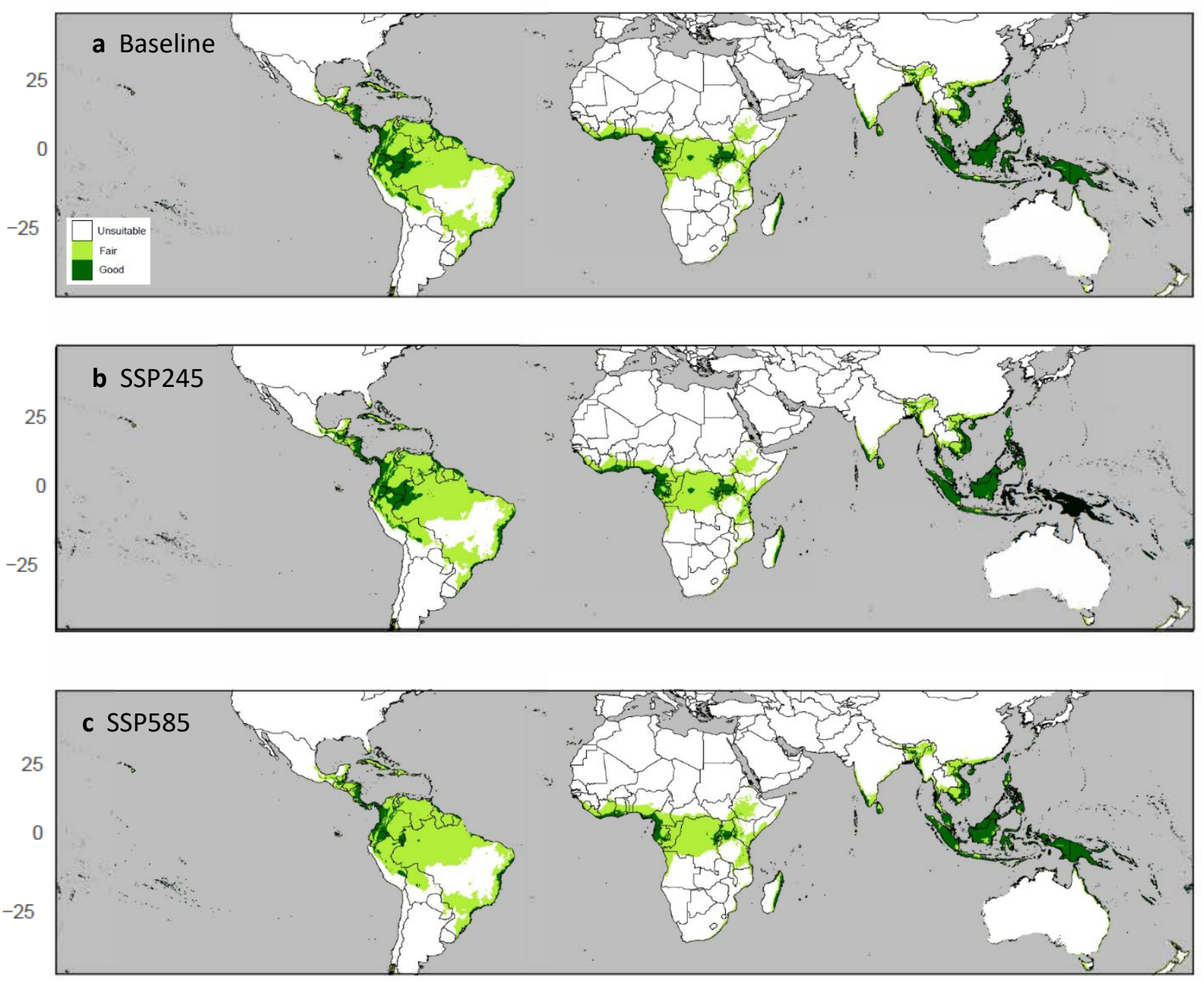

636 Supplementary Figure 2. Suitable Breadfruit Range (a) baseline (1970-2000), (b) Future Stabilization (2061-

637 2080), and (c) Future High Emissions (2061-2080) scenarios with country outlines using average values from a

638 weighted SDM ensemble projected using a CMIP6 GCM ensemble of opportunity under SSPs 2 and 5. 